\title{
Melorheostosis of the Fossa Intercondylaris Femoris - A Case Report and Review of the Literature
}

\author{
Helmut Ahrens ${ }^{1}$, Christoph Theil ${ }^{1}$, Georg Gosheger ${ }^{1}$, Sebastian Mühl', Niklas Deventer ${ }^{1}$, Kristian \\ Nikolaus Schneider ${ }^{1}$
}

Learning Point of the Article:

Melorheostosis is a rare benign bone condition characterized by excessive segmental sclerosis of cortical bone being reminiscent of dripping candle wax. Manifold clinical manifestations like impingement or nerve compression syndromes are possible and potentially require surgical treatment.

\section{Abstract}

Introduction: Melorheostosis is a rare benign bone condition characterized by excessive segmental sclerosis of cortical bone being reminiscent of dripping candle wax. It typically affects the long bones and can cause impingement and nerve compression syndromes that may require surgical treatment.

Case Report: We report the case of a 49-year-old male patient with a 12-month history of the left-sided knee pain and a concomitant limitation of his left knee flexion to 90 degree. Radiographic and magnetic resonance imaging revealed the typical radiographic appearance of melorheostosis with an extraosseous lesion in the fossa intercondylaris femoris being causative for the limited knee range of motion. Following the resection of the extraosseous part of the lesion through a direct open approach, the patient is pain free with a maximum of 110 degree knee flexion at 12 month follow-up.

Conclusion: Melorheostosis can present with manifold clinical manifestations that potentially require surgical treatment. Even in patients with a challenging localization of extraosseous lesions, a good to excellent functional outcome is possible.

Keywords: Melorheostosis, Léri disease, Candle wax disease, Surgery, Fossa intercondylaris femoris, Notch.

\section{Introduction}

Melorheostosis is a rare benign bone condition, first described in 1922 by Léri and Joanny [1]. Although several eponyms such as "Léri disease" and "candle wax disease" are known, its incidence is reported to be only 0.9 per 1 million population [2, $3,4]$. It typically manifests during early childhood and adolescence with $40-50 \%$ of all cases being evident by the age of $20[2]$.

\section{Case Report}

We present the case of a 49 -year-old male patient $(1.83 \mathrm{~m}, 88 \mathrm{~kg})$ with a 12-month history of left-sided knee pain with concomitant limitation of the knee flexion to 90 degree. The initial conservative treatment consisted of analgesics and physiotherapy. Persistent pain led to subsequent radiographic (Fig. 1a and b) and magnetic resonance imaging (Fig. 2a-c) that revealed an excessive hyperostosis of the left femur with an extraosseous lesion in the fossa intercondylaris femoris. The patient was subsequently referred to our specialized center for musculoskeletal oncology.

Based on the clinical and radiographic findings, we established the diagnosis of melorheostosis and the patient underwent surgical resection of the symptomatic extraosseous lesion in the fossa intercondylaris through a direct open approach under meticulous protection of the cruciate ligaments. Postoperatively, the histological findings were consistent with the diagnosis of melorheostosis (Fig. 3) and the patient was

\section{Author's Photo Gallery}

\begin{tabular}{|c|}
\hline Access this article online \\
\hline $\begin{array}{c}\text { Website: } \\
\text { www.jocr.co.in }\end{array}$ \\
\hline DOI: \\
10.13107/jocr.2021.v11.04.2146 \\
\hline
\end{tabular}

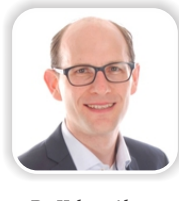

Dr. Helmut Ahrens

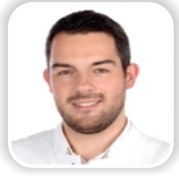

Dr. Christoph Theil

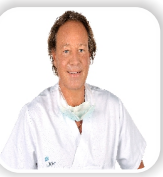

Dr. Georg Gosheger

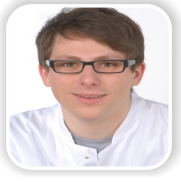

Dr. Sebastian Mühl

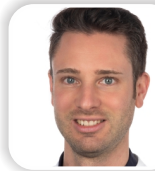

Dr. Niklas Devente

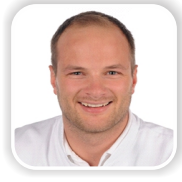

Dr. Kristian Nikolaus Schneider
Department of Orthopaedics and Tumor Orthopaedics of the University Hospital of Münster, Germany.

${ }^{2}$ Department of Pathology, University Hospital of Münster, Germany.

Address of Correspondence:

Dr. med. Kristian Nikolaus Schneider,

Hammer Straße 8, 48153 Münster, Germany

E-mail: kristian.schneider.mh@gmail.com

Journal of Orthopaedic Case Reports | pISSN 2250-0685 | eISSN 2321-3817 | Available on www.jocr.co.in | doi:10.13107/jocr.2021.v11.i04.2146 This is an Open Access article distributed under the terms of the Creative Commons Attribution Non-Commercial License (http://creativecommons.org/licenses/by-nc/3.0) which permits unrestricted non-commercial use, distribution, and reproduction in any medium, provided the original work is properly cited. 


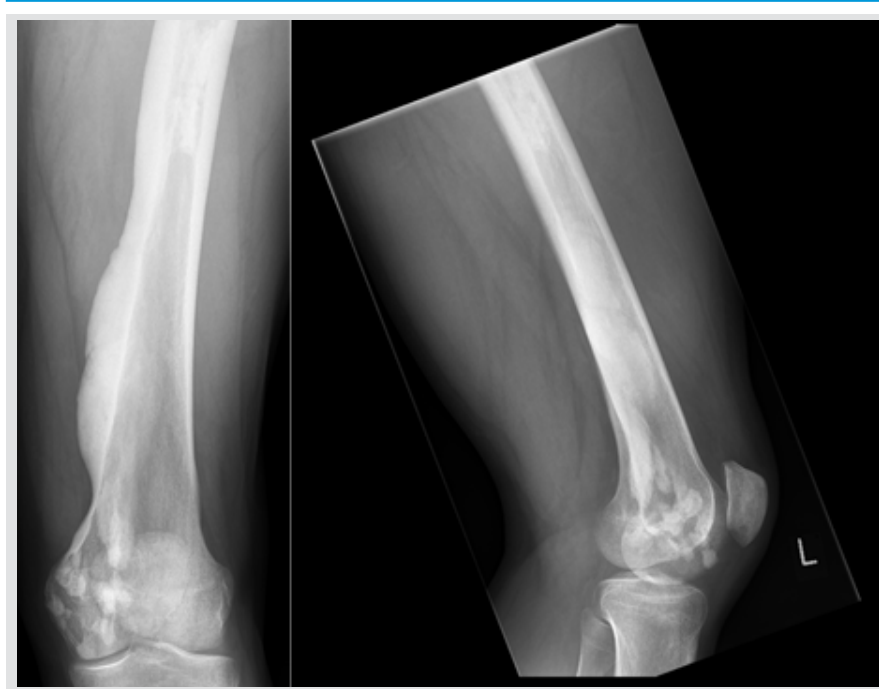

Figure 1: ( $\mathrm{a}$ and $\mathrm{b}$ ) Radiographic appearance of melorheostosis with typical excessive segmental sclerosis of the cortical bone being reminiscent of dripping candle wax.

allowed full weight-bearing with no limitation to the range of motion of the left knee joint.

At 6-week follow-up, the patient reported no persisting pain but a lasting limitation to his left knee flexion that was subsequently addressed with an intensive physiotherapeutic treatment. At 12-month follow-up, the patient was pain free and showed an improved knee flexion to 110 degree.

\section{Discussion}

The precise etiology of melorheostosis remains unclear $[5,6$, 7]. However, more recently, Kang et al. identified somatic mosaic mutations in the regulatory domain of the MAP2K1 kinase which seem to be causative for the development of melorheostosis in some, but not all patients $[6,7]$. Although this potentially opens possibilities of a targeted treatment, Wordsworth and Chan strengthen that targeting the MAP pathway will also affect not mutated cells resulting in potential off-target side effects [7].

While only around 500 cases of melorheostosis are reported in

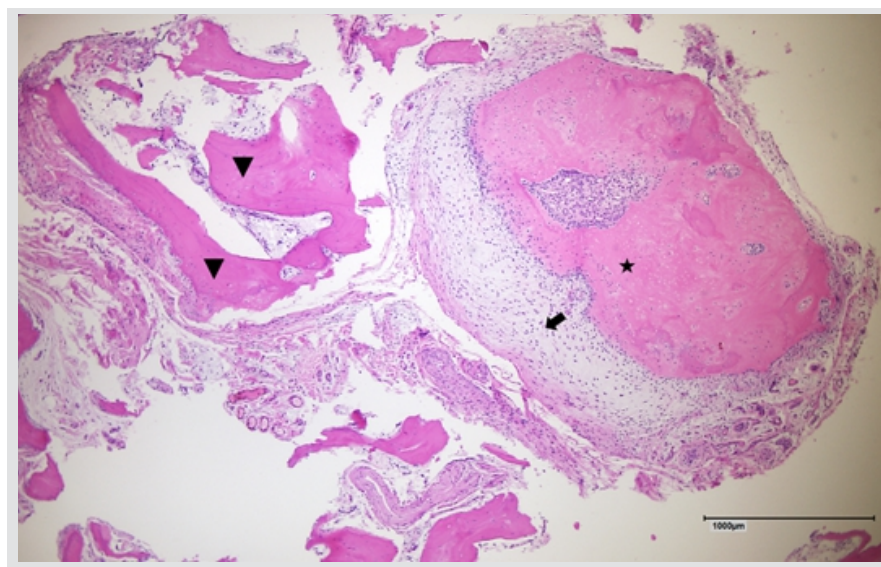

Figure 3: Histologic features of melorheostosis in hematoxylin and eosin staining $(\times 40)$ : Junio woven bone $\left({ }^{*}\right)$ in transition to chondromyxoid area (arrow) next to older sclerotized lamellar bone (arrowheads).

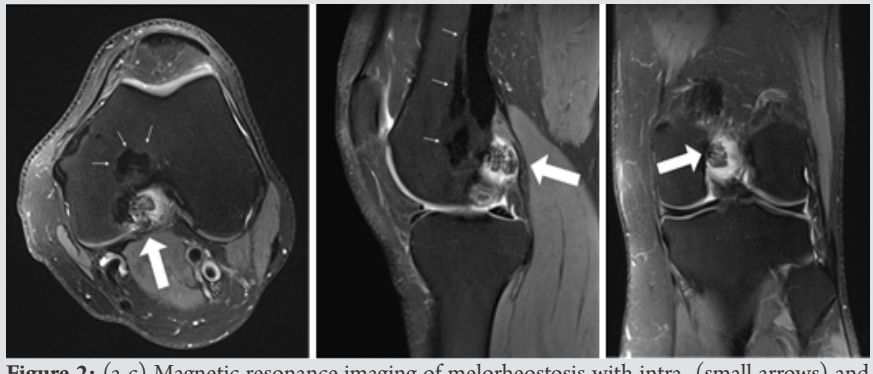

Figure 2: (a-c) Magnetic resonance imaging of melorheostosis with intra- (small arrows) and extraosseous lesions and the symptomatic lesion in the fossa intracondylaris femoris (big arrow).

literature, Smith et al. presented the largest single-center cohort of this entity in 2016 with 24 patients aged 3-68 years [7, 8]. Although no gender predilection has previously been reported, they found an unexpected and yet inexplicable female to male ratio of 4:1 [8]. Predominant affected bones in their cohort were the leg (67\%), ankle or foot (38\%), and the arm (33\%) with 20 patients $(83 \%)$ reporting a single limb involvement and 4 patients (17\%) multiple affected body regions [8]. Of the three major clinical manifestations pain, limited range of motion, and deformity, pain was the most frequent clinical appearance in their cohort with 20 patients (83\%) complaining of nociceptive, neuropathic, or skeletal pain [8].

The typical radiographic appearances of melorheostosis are excessive segmental sclerosis of cortical bone being reminiscent of the eponymous dripping candle wax [7]. Although these findings are characteristic for melorheostosis, they are not consistent and differential diagnosis to other sclerosing bone conditions can be challenging [7].

Clinical manifestations can require a surgical treatment, especially in patients where lesions cause nerve compressions or impingement syndromes [7]. Several authors report the surgical treatment of melorheostosis around the knee: John et al. reported a 42-year-old female patient that underwent repeated open excision of intra-articular lesions to the patellofemoral joint [9]. Moulder and Marsh reported a 40year-old male patient who underwent total knee arthroplasty after a 9-year long history of symptoms and two previous arthroscopic removal of loose bodies [10]. Several authors strengthen the necessity of repeated surgeries in these patients with Smith et al. reporting that 54\% of patients in their cohort had to undergo a mean number of two surgeries and conclude that a progressive nature of melorheostosis is likely [8].

When classifying our presented case in the literature, we find a typical melorheostosis manifestation of the long bone but report a previously not described appearance of an extraosseous lesion in the intercondylar notch. While future revision surgery seems statistically likely in our patient, he currently remains pain free and satisfied with the post-operative functional improvements at 12-month follow-up. 


\section{Conclusion}

Melorheostosis can have manifold clinical appearances that potentially require surgical treatment. Although subsequent revision surgeries to address new or repeated lesions cannot be precluded, a good to excellent functional outcome is possible. Nevertheless, melorheostosis remains a diagnosis that should be treated by orthopedic surgeons specialized in musculoskeletal oncology.

\section{Clinical Message}

Melorheostosis is a rare benign bone condition characterized by excessive segmental sclerosis of cortical bone being reminiscent of dripping candle wax. Clinical manifestations vary, but in patients with pain, deformity, and/or limited range of motion, surgical treatment might be required.

\section{References}

1. Joanny L. Une affection non decrite des os. hyperostose en coulee sur toute la longueur d'un membre ou melorheostose. Bull Mem Soc Med Hop Paris 1922;46:1141-9.

2. Gnoli M, Staals EL, Campanacci L, Bedeschi MF, Faletra F, Gallone S, et al. Melorheostosis and osteopoikilosis clinical and molecular description of an Italian case Series. Calcified Tissue Int 2019; 105:215-21.

3. Suresh S, Muthukumar T, Saifuddin A. Classical and unusual imaging appearances of melorheostosis. Clin Radiol 2010;65:593-600.

4. Taybi H, Lachman RS, Merten DF. Radiology of syndromes, metabolic disorders, and skeletal dysplasias. Invest Radiol $1993 ; 28: 266$.

5. Fick CN, Fratzl-Zelman N, Roschger P, Klaushofer K, Jha S, Marini JC, Bhattacharyya T. Melorheostosis: A clinical, pathologic, and radiologic case series. Am J Surg Pathol
2019;43:1554-9.

6. Kang H, Jha S, Deng Z, Fratzl-Zelman N, Cabral WA, Ivovic $\mathrm{A}$, et al. Somatic activating mutations in MAP2K1 cause melorheostosis. Nat Commun 2018;9:1390.

7. Wordsworth P, Chan M. Melorheostosis and osteopoikilosis: A review of clinical features and pathogenesis. Calcified Tissue Int 2019; 104:530-43.

8. Smith GC, Pingree MJ, Freeman LA, Matsumoto JM, Howe $\mathrm{BM}$, Kannas SN, et al. Melorheostosis: A retrospective clinical analysis of 24 patients at the mayo clinic. PM R 2017;9:283-8.

9. John B, Sharma A, Pandey RA. Managing recurrence in intraarticular melorheostosis involving the knee joint: A case report.J Orthop Case Rep 2017;7:29-33.

10. Moulder E, Marsh C. Soft tissue knee contracture of the knee due to melorheostosis, treated by total knee arthroplasty. Knee 2006;13:395-6.
Conflict of Interest: Nil

Source of Support: Nil

Consent: The authors confirm that informed consent was obtained from the patient for publication of this case report
How to Cite this Article

Ahrens H, Theil C, Gosheger G, Mühl S, Deventer N, Schneider KN. Melorheostosis of the Fossa Intercondylaris Femoris - A Case Report and Review of the Literature. Journal of Orthopaedic Case Reports 2021 April;11(4):45-47. 